\title{
Construct Validity and Reliability of the European Organization for Research and Treatment of Cancer Quality of Life Tool Among Colorectal Cancer Patients in Ethiopia
}

Lidya Genene Abebe ( $\sim$ lidyagenene@gmail.com )

Addis Ababa University https://orcid.org/0000-0002-6128-4495

Abigiya Wondimagegnehu

Addis Ababa University

Aynalem Abraha Woldemariam

Addis Ababa University

Bizu Gelaye

Harvard University

Eva Johanna Kantelhardt

Martin-Luther-Universitat Halle-Wittenberg

Adamu Addissie

Addis Ababa University

Research Article

Keywords: Validity, EORTC-QLQ, colorectal cancer, Ethiopia

Posted Date: June 22nd, 2021

DOI: https://doi.org/10.21203/rs.3.rs-623547/v1

License: (c) (1) This work is licensed under a Creative Commons Attribution 4.0 International License.

Read Full License 


\section{Abstract}

Background: Colorectal cancer and its treatments can have a detrimental effect on patients' quality of life. The European Organization for Research and Treatment of Cancer Quality of Life questionnaire (EORTC-QLQ) was developed to assess quality of life among colorectal cancer patients and is used worldwide. However, the tool has not been translated into a local language or validated in the Ethiopian context. Therefore, this study aimed to examine the psychometric properties of the EORTC-QLQ in Ethiopia among colorectal cancer patients.

Methods: A cross-sectional study was conducted in a major referral hospital in Addis Ababa, Ethiopia from March to May, 2020. A total of 158 colorectal cancer patients were consecutively included. The construct validity was assessed using Multitrait Scale Analysis, convergent validity, and relationship with functional outcomes. The internal consistency was examined using Cronbach's alpha.

Result: Among the participants, $52.2 \%$ were men, with a median age of 46 years (IQR $=17.7$ years). The time needed to complete the EORTC-QLQ was less than 20 minutes. The item-total correlation alpha values ranged from $0.47-0.91$. All item correlations within their scales were greater than 0.4 except for the Blood and Mucus in Stool scale. The value of correlation coefficients between all items and their own domain were higher than other domains, except for the Blood and Mucus in Stool scale. The correlation between the core questionnaire and the colorectal tool ranged from -0.453-0.581. The tool showed a significant difference between stoma and non-stoma patients, and between patients who had good physical function and those who did not.

Conclusion: Except for the Blood and Mucus in Stool scale, the construct validity and reliability of all scales were supported. Therefore, the Amharic version of the tool can be used to assess health related quality of life in Ethiopian colorectal cancer patients. However, due to the low correlation between items in the Blood and Mucus in Stool scale, we recommend that these items are treated as a single item.

\section{Introduction}

Colorectal cancer is the third leading cause of cancer cases worldwide. In 2018, there were more than 1.8 million new cases and 881,000 deaths from colorectal cancer [1]. The incidence of colorectal cancer is higher in high-income countries, but the mortality is higher in low- and middle-income countries. In Eastern Africa, colorectal cancer was the fourth most frequently diagnosed cancer type [2]. In Ethiopia, the second most populous country in sub-Saharan Africa, colorectal is the most common cancer diagnosis in males and it ranks fourth in females [3]. It is also responsible for 11.2 percent of cancer-related deaths in males and 4.8 percent of cancer-related deaths in females in Ethiopia.

Cancer symptoms and cancer treatments have several adverse effects and toxicity, which affect quality of life [4]. For instance, gastrointestinal cancer patients have been reported to suffer from problems that emerged as a consequence of both the disease and the treatments, which negatively affect their quality of life [5]. Colorectal cancer patients have significantly lower physical, role, cognitive and social function 
compared to the general public. Moreover, they have a higher frequency of constipation, diarrhoea and financial difficulties [6-8]. Thus, it is recommended to collect information on health-related quality of life and use this to guide decision making in treatment choice [9].

The World Health Organization (WHO) defines quality of life as a broad concept that depends on a person's physical health, psychological state, level of freedom, social relationships, and personal beliefs [10]. Cancer treatments have started incorporating quality of life as an end point [11]. Thus, different sensitive, reliable and validated tools are available to assess quality of life among cancer patients. Frequently used tools are the core EORTC-QLQ, the Functional Assessment of Chronic Illness Therapy (FACIT) Measurement System, the Rotterdam Symptom Checklist (RSCL), and the Symptom Distress Scale (SDS) [12]. From them, the core EORTC-QLQ has been recommended to be used when the aim of the study is to assess disease-specific symptoms $[13,14]$. To complement the core EORTC-QLQ, different disease-specific modules have been developed, and the EORTC-QLQ for colorectal cancer patients (EORTC-QLQ-CR29) is one of these tools. This tool has been developed to be used alongside the core tool in colorectal cancer patients. This disease-specific tool has been validated in different countries such as Spain, Taiwan, Korea and China [15-18]. Even though the Ethiopian Federal Ministry of Health has developed a strategy to assess and treat distressing symptoms in cancer patients [19], there are no validated tools to assess quality of life among colorectal cancer patients. Therefore, this study intended to examine the reliability and construct validity of EORTC-QLQ-CR29 tool in Ethiopian colorectal cancer patients.

\section{Materials And Methods}

\section{Study design, area and participants}

A cross-sectional study was carried out at Tikur Anbessa Specialized Hospital (TASH) from March to May, 2020. TASH is the largest referral and teaching hospital in Ethiopia, serving as the only radiotherapy centre in the country. In this oncology centre, there are two radiotherapy machines, 36 inpatient beds and 12 outpatient chemotherapy beds. There are also six clinical oncologists who provide the oncology services [20].

The sample size was calculated based on the recommendations given for scaling analysis [21, 22]. Since Amharic is the official working language of Ethiopia and is spoken by millions of Ethiopians as a second language, 158 pathologically-confirmed colorectal cancer patients who were $\geq 18$ years old and who could speak Amharic were consecutively included while attending the TASH oncology department.

\section{Instrument}

EORTC-QLQ-CR29 is a 29-item module developed to complement the core EORTC-QLQ. It comprises 19 single items and four scales to assess urinary frequency, blood or mucus in the stool, stool frequency, body image and other problems faced by patients. The tool scales are generally classified as functional 
and symptom scales [23]. Along with the colorectal tool, the core EORTC-QLQ and an intervieweradministered structured questionnaire were used to assess participants' sociodemographic and clinical characteristics.

The EORTC-QLQ-CR29 tool was translated into Amharic according to the EORTC translation guidelines [24]. A pilot study was conducted to identify difficult, confusing and upsetting questions. None of the questions were found to be difficult, confusing or upsetting for the participants. Based on the recommendations for pilot studies [24], ten colorectal cancer patients were included in the pilot and these participants were excluded from the actual study.

After the completion of the pilot, the data collection commenced. The data was collected by two nurses who have bachelor's degrees and work in the oncology centre. Training on how to collect the data was given to the data collectors by the principal investigator for three days, focusing on the purpose of the study, contents of the questionnaire, and how to approach and get consent from patients. The principal investigator supervised the data collection process every other day to monitor the data collection procedure. Patients were approached in the waiting room while waiting for their turns.

\section{Data analysis}

Descriptive statistics were used to assess the frequency distributions of socio-demographic characteristics and clinical data. Numbers and percentages were used for categorical variables and median and inter-quartile range were used for continuous variables. The acceptability of the EORTC-QLQCR29 was assessed in term of response rate, missing data and time needed to complete the questionnaire. The reliability was assessed using Cronbach's alpha. A value of Cronbach's alpha of 0.70 or greater was considered to be adequate [22].

Convergent validity, the extent to which two measures are related to the same construct, was determined by employing Multitrait scaling analysis. Multitrait scaling analysis focuses on items as the unit of analysis [22].

Known-groups validity was checked using the Mann-Whitney test to see whether the tool is able to detect differences between groups. The known groups that were used for comparison were treatment intent, physical function, and presence of stoma [23]. Based on the median value of the physical scale of the core EORTC-QLQ, patients were classified as having better or worse physical function. Those patients with a median score of $\geq 43.3$ for the physical scale were considered to have better physical function, whereas those below 43.3 were considered to have worse physical function [25].

The correlations between the items of the colorectal cancer and core tools scales were determined using Spearman's correlation coefficient. All scales and items were transformed into a 0-100 score as per the EORTC-QLQ scoring manual [26]. Statistical analyses were performed using SPSS version 21.

\section{Results}




\section{Socio-demographic characteristics of respondents}

A total of 158 participants were included in this study, with a median age of 46 (IQR $=17.7$ ). About 50 $(32.3 \%)$ study participants had no formal education and were employed (32.3\%), while 45 (28.5\%) respondents had attended college. The majority of the study participants were men (52.5\%), married (63.3\%), and residents of Addis (64.4\%). 
Table 1

Socio-demographic characteristics of respondents at Tikur Anbessa Specialized Hospital, Addis Ababa, 2020

\begin{tabular}{|c|c|c|c|}
\hline Variable & Category & Frequency $(n=158)$ & Percent (\%) \\
\hline \multirow[t]{2}{*}{ Sex } & Men & 83 & 52.5 \\
\hline & Women & 75 & 47.5 \\
\hline \multirow[t]{4}{*}{ Educational status } & No formal education & 51 & 32.3 \\
\hline & Primary education & 35 & 22.2 \\
\hline & Secondary education & 27 & 17.1 \\
\hline & College and above & 45 & 28.5 \\
\hline \multirow[t]{6}{*}{ Occupation } & Farmer & 11 & 7 \\
\hline & Employed & 51 & 32.3 \\
\hline & Housewife & 51 & 32.3 \\
\hline & Retired & 11 & 7 \\
\hline & Student & 19 & 12 \\
\hline & Merchant & 15 & 9.5 \\
\hline \multirow[t]{4}{*}{ Region } & Addis Ababa & 102 & 64.6 \\
\hline & Oromia & 27 & 17.1 \\
\hline & Amhara & 17 & 10.8 \\
\hline & Others* & 12 & 7.5 \\
\hline \multirow[t]{4}{*}{ Marital status } & Married & 100 & 63.3 \\
\hline & Single & 28 & 17.7 \\
\hline & Divorced & 13 & 8.2 \\
\hline & Widowed & 17 & 10.8 \\
\hline \multirow[t]{3}{*}{ Age } & $18-45$ & 132 & 41.8 \\
\hline & $46-65$ & 170 & 53.8 \\
\hline & $>65$ & 14 & 4.4 \\
\hline
\end{tabular}

\section{Clinical characteristics of respondents}


Rectal cancer accounted for 85 (53.8\%) respondents. Seventy-eight $(49.4 \%)$ of respondents were being treated with chemotherapy alone. About $120(75.9 \%)$ of respondents were treated with palliative intent. The majority of (72.2\%) respondents were stage four cancer patients (Table 2).

\section{Table 2}

Clinical characteristics of respondents in Tikur Anbessa Specialized Hospital, Addis Ababa, 2020

\begin{tabular}{|c|c|c|c|}
\hline Variables & Category & Frequency $(n=158)$ & Percent (\%) \\
\hline \multirow[t]{2}{*}{ Cancer site } & Colon & 73 & 46.2 \\
\hline & Rectum & 85 & 53.8 \\
\hline \multirow[t]{6}{*}{ Type of treatment } & Chemotherapy only & 78 & 49.4 \\
\hline & Surgery and radiotherapy only & 16 & 10.1 \\
\hline & Chemotherapy and surgery only & 34 & 21.5 \\
\hline & Chemotherapy and radiotherapy only & 17 & 10.8 \\
\hline & $\mathrm{CSR}^{*}$ & 12 & 7.6 \\
\hline & Radiotherapy only & 1 & 0.6 \\
\hline \multirow[t]{2}{*}{ Treatment intent } & Curative & 38 & 24.1 \\
\hline & Palliative & 120 & 75.9 \\
\hline \multirow[t]{4}{*}{ Cancer stage } & Stage I & 7 & 4.4 \\
\hline & Stage II & 24 & 15.2 \\
\hline & Stage III & 13 & 8.2 \\
\hline & Stage IV & 114 & 72.2 \\
\hline
\end{tabular}

\section{Acceptability of EORTC-QLQ-CR29}

The acceptability of the tool was assessed in terms of response rate, missing data and time needed to complete the questionnaire. The EORTC-QLQ-CR29 along with the core EORTC-QLQ tool took an average of 20 minutes to complete. There were no missing responses to the questionnaire. In general, the tool was found to be acceptable.

\section{Reliability of EORTC-QLQ-CR29}

The reliability of the tool was examined based on the value of Cronbach's alpha coefficients (alpha $\geq$ 0.70). As presented in Table 3, all of the scales had an alpha value greater than or equal to 0.7 , except for the Mucus and Blood in Stool scale (0.47). Urinary Frequency had the highest alpha value (0.91), followed by Stool Frequency $(0.85)$. 
Table 3

Cronbach's alpha values of EORTC-QLQ-CR29 scales in Tikur Anbessa Specialized Hospital, Addis Ababa, 2020.

\begin{tabular}{|lll|}
\hline Scale name & Number of items & Cronbach's alpha coefficients \\
\hline Urinary Frequency & 2 & 0.91 \\
\hline Mucus and Blood in Stool & 2 & 0.47 \\
\hline Body Image & 3 & 0.70 \\
\hline Stool Frequency & 2 & 0.85 \\
\hline
\end{tabular}

\section{Construct validity}

\section{Convergent and divergent validity results of Multitrait scaling analysis for EORTC-QLQ-CR29}

Convergent and divergent validity were assessed in terms of item-own scale and item-other scale correlation, respectively. The item-own scale correlation was over 0.4 for all scales. Similarly, item-own correlation for all scales was higher than item-other scale correlation. As seen in Table 6, except for the Blood and Mucus in Stool scale, all scales have an item-own correlation above 0.4 and an item-other scale correlation below the item-own scale correlation of 0.4 .

Table 4

Construct validity for EORTC-QLQ-CR29 scales in Tikur Anbessa Specialized Hospital, Addis Ababa, 2020.

\begin{tabular}{|llllll|}
\hline Scale & $\begin{array}{l}\text { Item } \\
\text { numbers }\end{array}$ & $\begin{array}{l}\text { Item-own } \\
\text { scale } \\
\text { correlation }\end{array}$ & $\begin{array}{l}\text { Item-own scale correlation } \\
\text { after correction overlap }\end{array}$ & $\begin{array}{l}\text { Item-other } \\
\text { scale } \\
\text { correlation }\end{array}$ & $\begin{array}{l}\text { P- } \\
\text { value }\end{array}$ \\
\hline $\begin{array}{l}\text { Urinary } \\
\text { Frequency }\end{array}$ & 31,32 & $0.94-0.96$ & 0.81 & $-0.33-0.34$ & $<$ \\
$\begin{array}{l}\text { Blood and } \\
\text { Mucus in } \\
\text { Stool }\end{array}$ & 38,39 & $0.74-0.79$ & 0.24 & $-0.31-0.35$ & 0.001 \\
\hline $\begin{array}{l}\text { Stool } \\
\text { Frequency }\end{array}$ & 52,53 & $0.92-0.93$ & 0.73 & & 0.001 \\
\hline Body Image & $45-47$ & $0.75-0.81$ & $0.51-0.55$ & $-0.33-0.35$ & $<$ \\
\hline
\end{tabular}

\section{The correlation between the core EORTC-QLQ and CR29 scales}


The correlation between the core EORTC-QLQ and CR29 scales ranged from - 0.45-0.58. The highest correlation was seen between the Body Image scale from the colorectal tool and the Emotional scale from the core questionnaire. The highest negative correlation was observed between Flatulence and Cognitive Function $(r=-0.45)$. Most of the correlations between the core EORTC-QLQ and CR29 were below 0.4 (Table 5). 
Table 5

The correlation between the core EORTC QLQ and CR 29 scales in Tikur Anbessa Specialized Hospital, Addis Ababa, 2020

\begin{tabular}{|c|c|c|c|c|c|c|c|c|c|}
\hline & PF & RF & PA & FA & NV & CF & $\mathrm{EF}$ & SF & QoL \\
\hline $\begin{array}{l}\text { Urinary } \\
\text { Frequency }\end{array}$ & -0.04 & -0.02 & -0.00 & 0.01 & 0.01 & 0.11 & $-0.23^{a}$ & $-0.17^{b}$ & 0.12 \\
\hline $\begin{array}{l}\text { Urinary } \\
\text { Incontinence }\end{array}$ & $-0.24^{a}$ & $-0.22^{a}$ & $0.17^{b}$ & $0.17^{b}$ & 0.14 & $-0.218^{a}$ & $-0.21^{a}$ & $-0.39^{a}$ & 0.09 \\
\hline Dysuria & $-0.27^{a}$ & $-0.34^{a}$ & $0.30^{\mathrm{a}}$ & $0.23^{a}$ & $0.43^{\mathrm{a}}$ & $-0.21^{a}$ & $-0.33^{a}$ & $-0.32^{a}$ & -0.13 \\
\hline $\begin{array}{l}\text { Abdominal } \\
\text { Pain }\end{array}$ & -0.14 & -0.11 & $0.37^{a}$ & $0.36^{\mathrm{a}}$ & $0.24^{a}$ & -0.14 & -0.08 & -0.02 & 0.07 \\
\hline Buttock Pain & -0.13 & $-0.18^{b}$ & 0.09 & 0.02 & $0.24^{\mathrm{a}}$ & 0.10 & -0.14 & $-0.21^{a}$ & $-0.19^{b}$ \\
\hline Bloating & $-0.27^{a}$ & $-0.23^{a}$ & $0.21^{a}$ & $0.25^{\mathrm{a}}$ & $0.17^{a}$ & $-0.19^{a}$ & $-0.31^{a}$ & -0.13 & 0.09 \\
\hline $\begin{array}{l}\text { Blood and } \\
\text { Mucus in Stool }\end{array}$ & $-0.17^{b}$ & -0.10 & $0.24^{\mathrm{a}}$ & $0.35^{\mathrm{a}}$ & $0.18^{b}$ & $-0.35^{a}$ & $-0.17^{b}$ & -0.078 & $0.26^{a}$ \\
\hline Dry Mouth & $-0.30^{a}$ & -0.13 & $0.20^{\mathrm{a}}$ & $0.33^{a}$ & 0.02 & $-0.24^{a}$ & $-0.21^{a}$ & -0.15 & $0.24^{\mathrm{a}}$ \\
\hline Hair Loss & $-0.35^{a}$ & $-0.27^{a}$ & $0.36^{\mathrm{a}}$ & $0.30^{\mathrm{a}}$ & $0.38^{a}$ & $-0.36^{a}$ & -0.09 & $-0.20^{b}$ & 0.04 \\
\hline Taste & $-0.31^{a}$ & $-0.33^{a}$ & $0.39^{a}$ & $0.44^{\mathrm{a}}$ & $0.32^{\mathrm{a}}$ & $-0.32^{a}$ & -0.06 & $-0.16^{b}$ & -0.03 \\
\hline Anxiety & $0.29^{a}$ & $0.28^{\mathrm{a}}$ & -0.02 & -0.05 & -0.01 & -0.07 & $0.33^{a}$ & $0.23^{a}$ & 0.10 \\
\hline Weight & $0.31^{a}$ & $0.24^{\mathrm{a}}$ & -0.11 & -0.15 & $-0.20^{a}$ & $0.21^{a}$ & $0.32^{\mathrm{a}}$ & $0.31^{a}$ & -0.05 \\
\hline Body Image & $0.45^{\mathrm{a}}$ & $0.26^{a}$ & $-0.30^{a}$ & $-0.29^{a}$ & $-0.22^{a}$ & $0.25^{a}$ & $0.58^{a}$ & $0.29^{a}$ & 0.00 \\
\hline Flatulence & $-0.41^{a}$ & $-0.30^{a}$ & $0.36^{\mathrm{a}}$ & 0.11 & $0.35^{\mathrm{a}}$ & $-0.45^{a}$ & -0.12 & $-0.28^{a}$ & 0.15 \\
\hline $\begin{array}{l}\text { Faecal } \\
\text { Incontinence }\end{array}$ & $-0.32^{a}$ & $-0.40^{a}$ & $0.29^{a}$ & 0.16 & $0.30^{\mathrm{a}}$ & $-0.42^{\mathrm{a}}$ & $-0.32^{\mathrm{a}}$ & $-0.37^{a}$ & 0.04 \\
\hline Sore Skin & $-0.21^{\mathrm{a}}$ & $-0.36^{a}$ & $0.28^{a}$ & 0.03 & $0.37^{a}$ & -0.14 & $-0.31^{a}$ & $-0.27^{a}$ & 0.08 \\
\hline $\begin{array}{l}\text { Stool } \\
\text { Frequency }\end{array}$ & $-0.23^{a}$ & $-0.31^{a}$ & $0.17^{b}$ & 0.11 & $0.18^{\mathrm{b}}$ & 0.04 & $-0.38^{a}$ & $-0.16^{b}$ & -0.07 \\
\hline Embarrassment & -0.13 & $-0.16^{b}$ & 0.03 & 0.08 & 0.07 & 0.04 & $-0.30^{a}$ & -0.14 & 0.10 \\
\hline $\begin{array}{l}\text { Stoma Care } \\
\text { Problem }\end{array}$ & -0.15 & -0.12 & 0.03 & -0.08 & -0.03 & 0.08 & $-0.26^{a}$ & -0.15 & -0.06 \\
\hline
\end{tabular}

b. Correlation is significant at the 0.05 level, ${ }^{\text {a. }}$ Correlation is significant at the 0.01 level, PF: Physical Function, RF: Role Function, PA: Pain, FA: Fatigue, NV: Nausea and Vomiting, CF: Cognitive Function, EF: Emotional Function, SF: Social Function, QoL: Quality of Life 


\begin{tabular}{|c|c|c|c|c|c|c|c|c|c|}
\hline & PF & RF & PA & FA & NV & CF & $\mathrm{EF}$ & SF & QoL \\
\hline $\begin{array}{l}\text { Sexual Interest } \\
\text { Men }\end{array}$ & -0.14 & -0.09 & 0.05 & 0.11 & 0.03 & 0.03 & 0.02 & $-0.17^{b}$ & -0.12 \\
\hline Impotence & 0.03 & 0.14 & -0.09 & -0.08 & -0.17 & -0.01 & -0.04 & 0.03 & 0.15 \\
\hline $\begin{array}{l}\text { Sexual Interest } \\
\text { Women }\end{array}$ & -0.08 & -0.08 & 0.06 & -0.09 & -0.14 & -0.04 & -0.05 & 0.01 & 0.17 \\
\hline Dyspareunia & 0.08 & 0.11 & -0.07 & 0.07 & 0.10 & 0.00 & 0.05 & -0.07 & -0.12 \\
\hline
\end{tabular}

\section{Known-groups validity of EORTC-QLQ-CR29}

To assess the known-groups validity of the tool, comparisons of scores of multi-item scales and single items of EORTC-QLQ-CR29 among three clinically-distinct groups were made. These three groups were treatment intent, presence of stoma and physical function. This study hypothesised that patients with a stoma had a higher symptom score for Embarrassment and lower functional score for the Anxiety and Body Image items and scale. Similarly, patients with worse physical health and palliative patients were expected to have higher scores for the symptom items and scales and lower scores for functional scales and items.

The Mann-Whitney test revealed that there was no significant difference between the curative and the palliative treatment groups in any of the scores of the colorectal tool scales or items. In patients with and without a stoma, the presence of a stoma led to a deterioration in quality of life by increasing Urinary Frequency, Flatulence, Embarrassment and Anxiety. Patients with better physical function scored higher for functional items and scales and scored lower for symptom items and scales. This suggested the known-groups validity of the tool is fulfilled. 
Table 6

Known-groups comparison: scales and items in the EORTC-QLQ-CR29 for clinically-distinct groups in Tikur Anbessa Specialized Hospital, Addis Ababa, 2020

\begin{tabular}{|c|c|c|c|c|c|c|c|c|c|}
\hline \multirow{3}{*}{$\begin{array}{l}\text { CR- } \\
29\end{array}$} & \multicolumn{3}{|c|}{ Treatment mean rank value } & \multicolumn{3}{|c|}{ Presence of stoma } & \multicolumn{3}{|c|}{ Physical function } \\
\hline & Curative & Palliative & $P$ & Yes & No & $P$ value & Worse & Better & p-value \\
\hline & $N=38$ & $N=120$ & & $N=60$ & $N=98$ & & $N=79$ & $N=79$ & \\
\hline BI & 76.03 & 80.60 & 0.84 & 79.01 & 79.80 & 0.92 & 66.99 & 92.01 & $<0.001$ \\
\hline AN & 78.25 & 79.90 & 1.00 & 65.95 & 87.80 & 0.002 & 74.37 & 84.63 & 0.13 \\
\hline WET & 76.22 & 80.54 & 0.99 & 80.73 & 78.74 & 0.78 & 73.11 & 85.89 & 0.07 \\
\hline SXM & 34.65 & 44.33 & 0.10 & 47.27 & 38.70 & 0.87 & 16.67 & 45.67 & 0.25 \\
\hline sXW & 36.28 & 38.54 & 0.64 & 39.18 & 37.30 & 0.49 & 43.13 & 31.81 & 0.07 \\
\hline UFR & 79.53 & 79.49 & 1.00 & 89.78 & 73.21 & 0.02 & 80.06 & 78.94 & 0.87 \\
\hline BM & 82.18 & 78.65 & 0.99 & 69.50 & 85.6 & 0.02 & 84.40 & 74.60 & 0.15 \\
\hline STF & 78.59 & 79.79 & 0.98 & 86.78 & 75.04 & 0.11 & 83.23 & 75.77 & 0.30 \\
\hline URI & 82.92 & 78.42 & 0.97 & 82.53 & 33.33 & 0.49 & 82.09 & 76.91 & 0.45 \\
\hline DY S & 87.25 & 77.05 & 0.80 & 77.85 & 80.51 & 0.70 & 89.18 & 69.82 & 0.00 \\
\hline ABP & 79.08 & 79.63 & 1.00 & 69.20 & 85.81 & 0.02 & 88.94 & 70.06 & 0.01 \\
\hline BTP & 74.57 & 81.06 & 0.86 & 84.89 & 76.20 & 0.23 & 82.50 & 76.50 & 0.39 \\
\hline BLO & 76.63 & 80.41 & 1.00 & 75.12 & 82.18 & 0.30 & 88.21 & 70.79 & 0.01 \\
\hline DRM & 75.83 & 80.66 & 0.87 & 80.37 & 78.97 & 0.84 & 91.20 & 67.80 & $<0.001$ \\
\hline HRL & 87.16 & 77.08 & 0.60 & 66.35 & 87.55 & $<0.001$ & 93.04 & 65.96 & $<0.001$ \\
\hline TAT & 75.39 & 80.80 & 0.99 & 68.37 & 86.32 & 0.01 & 90.32 & 68.68 & $<0.001$ \\
\hline FLU & 76.59 & 80.42 & 0.99 & 89.68 & 73.27 & 0.02 & 95.54 & 63.46 & $<0.001$ \\
\hline FEI & 74.55 & 81.07 & 1.00 & 88.01 & 74.29 & 0.05 & 87.53 & 71.47 & 0.02 \\
\hline sos & 77.55 & 80.12 & 0.96 & 80.12 & 79.12 & 0.89 & 84.40 & 74.60 & 0.16 \\
\hline EMB & 83.78 & 78.15 & 0.96 & 108.25 & 61.90 & $<0.001$ & 82.70 & 76.30 & 0.34 \\
\hline SCR & 34.19 & 29.48 & 0.47 & NA & NA & NA & 35.05 & 25.95 & 0.03 \\
\hline
\end{tabular}

Body image: Bl, Anxiety: AN, Weight: WET, Sexual interest (men): SXM, Sexual interest (women): SXF, Urinary frequency: UFR, Blood and mucus in stool: BM, Stool frequency: STF, Urinary incontinence: URI, Dysuria: DYS, Abdominal pain: ABP, Buttock pain: BTP, Bloating: BLO, Dry mouth: DRM, Hair loss: HRL, Taste: TAT, Flatulence: FLU, Faecal incontinence: FEl, Sore skin: SOS, Embarrassment: EMB, Stoma care problem: SCR, Impotence: IMP, Dyspareunia: DYP, Not applicable: NA 


\begin{tabular}{|c|c|c|c|c|c|c|c|c|c|}
\hline \multirow{3}{*}{$\begin{array}{l}\text { CR- } \\
29\end{array}$} & \multicolumn{3}{|c|}{ Treatment mean rank value } & \multicolumn{3}{|c|}{ Presence of stoma } & \multicolumn{3}{|c|}{ Physical function } \\
\hline & Curative & Palliative & $P$ & Yes & No & $P$ value & Worse & Better & p-value \\
\hline & $N=38$ & $N=120$ & & $N=60$ & $N=98$ & & $N=79$ & $N=79$ & \\
\hline IMP & 35.58 & 44.04 & 0.16 & 48.77 & 37.75 & 0.16 & 45.12 & 39.37 & 0.12 \\
\hline DYS & 43.47 & 36.27 & 0.64 & 34.91 & 39.84 & 0.37 & 35.57 & 40.93 & 0.23 \\
\hline \multicolumn{10}{|c|}{$\begin{array}{l}\text { Body image: BI, Anxiety: AN, Weight: WET, Sexual interest (men): SXM, Sexual interest (women): SXF, } \\
\text { Urinary frequency: UFR, Blood and mucus in stool: BM, Stool frequency: STF, Urinary incontinence: } \\
\text { URI, Dysuria: DYS, Abdominal pain: ABP, Buttock pain: BTP, Bloating: BLO, Dry mouth: DRM, Hair loss: } \\
\text { HRL, Taste: TAT, Flatulence: FLU, Faecal incontinence: FEl, Sore skin: SOS, Embarrassment: EMB, } \\
\text { Stoma care problem: SCR, Impotence: IMP, Dyspareunia: DYP, Not applicable: NA }\end{array}$} \\
\hline
\end{tabular}

\section{Discussion}

The purpose of this study was to examine the acceptability, reliability, and construct validity of the Amharic version of the EORTC-QLQ-CR29 in Ethiopian colorectal cancer patients. In our study, the tool was found to be reliable. Its internal consistency values ranged from 0.47-0.91. All scales had Cronbach's alpha values above 0.7, except for the Blood and Mucus in Stool scale. This finding concurs with the Dutch and original studies [23, 27]. However, this finding differed from Korean and Taiwanese studies $[16,17]$, which found Cronbach-alpha values greater than 0.7 for all scales.

All items correlations within their scales were greater than 0.4, except for the Blood and Mucus in Stool scale. This is similar to the results seen in a Spanish study [15]. However, this is inconsistent with the previous findings where it was shown that the Blood and Mucus in Stool scale had convergent and divergent validity $[16-18,23,27]$. The different findings reveal that limited variability in item score has an effect on correlation [28]. Thus, lower variability in our study might contribute to the difference. In fact, the items that comprise the Blood and Mucus in Stool scale may not be correlated.

Known group comparison was performed to check whether the tool was able to detect differences between distinct groups. Our findings are consistent with studies conducted in Spain, China and the Netherlands $[15,18,23,27]$, where the tool was found to differentiate between the groups. However, the Body Image and Sore Skin items did not discriminate between patients with and without stoma. This is inconsistent with previous findings where a difference was seen according to the presence of a stoma $[15,18,23,27]$. This difference might be due to the fact that, in our study, there was an age difference between stoma and non-stoma patients. However, the previous studies did not report the age of stoma and non-stoma patients. In the current study, patients in the stoma groups were older than those in the non-stoma groups. Based on a study conducted in Australia, elderly patients have a greater appreciation for their function and body image [29].

The correlation between the core EORTC-QLQ and CR29 ranged from weak to moderate. The highest correlation was observed between the Emotional and Body Image scales. This agrees with studies 
conducted in Korean and Spain $[15,17]$. This result suggests that the tools are designed to cover different dimensions of health-related quality of life. Therefore, the core questionnaire should be used along the specific modules.

\section{Strengths And Limitation Of The Study}

During translation of the tool, every step of the EORTC translation process was followed, under the supervision of the EORTC translation group. Nonetheless, this study had its own limitations. Even though patients were included irrespective of their place of residence, treatment and disease stage, most of them were in the final stages of cancer. This is because most cancer patients in Ethiopia come to hospital at the late stages of the disease. There is also a delay in diagnosis and a prolonged treatment waiting time. Thus, the generalisability of the finding for early stage patients cannot be ascertained.

\section{Conclusion}

The current study supported the acceptability, reliability, and validity of the Amharic version of the EORTCQLQ-CR29 in Ethiopian colorectal cancer patients. However, the construct validity of the Mucus and Blood in Stool scale was not supported. Based on the findings, we recommend the Mucus and Blood in Stool scale is separated and treated as a single item. We also recommend that researchers and clinicians use the core questionnaire alongside the disease-specific module while assessing health related quality of life in colorectal cancer patients. Specific support for each patient should be focused on the individual domains and items which eventually contribute to lower quality of life.

\section{Abbreviations}

EORTC-QLQ: European Organization for Research and Treatment of Cancer Quality of Life questionnaire, EORTC-QLQ-CR29: European Organization for Research and Treatment of Cancer Quality of Life questionnaire for colorectal cancer patients, FACIT: Functional Assessment of Chronic Illness Therapy, GLOBOCAN: Global Organization Board of Cancer Association Network, QoL: Quality of life, SDS: The Symptom Distress Scale, WHO: World Health Organization

\section{Declarations}

\section{Ethics approval and consent to participate}

Ethical clearance was obtained from the ethical clearance committee of Addis Ababa University (AAU) College of health science, school of public health ethical review committee. Permission to use the questionnaires was secured from the EORTC research group using an online form at https://qol.eortc.org/form. Informed written consent was given by all participants.

\section{Consent for publication}


Not applicable.

\section{Availability of data and materials}

The data are available from the corresponding author on reasonable request.

\section{Competing interests}

The authors declare that they have no competing interests.

\section{Funding}

This study was funded by Addis Ababa University for partial fulfilment of a Master's degree in Public Health with a Specialty in Epidemiology and Biostatistics by the first author.

\section{Authors' contributions}

L.G.A. and A.W. conceived the research idea. L.G.A. and A.W. conducted the cross-cultural adaptation of the EORTC QLQ CR29; L.G.A., A.W. and A.A. conducted data analysis and interpretation; the manuscript was drafted by L.G.A.; L.G.A., A.W., A.A., A.A.W., B.G. and E.J.K. reviewed and edited the manuscript. All authors read and approved the final manuscript.

\section{Acknowledgments}

The authors would like to thank Addis Ababa University for funding this study. We would like to express our sincere gratitude to all participants and those who supported the study.

\section{References}

1. Bray F, Ferlay J, Soerjomataram I, Siegel RL. Global Cancer Statistics 2018: GLOBOCAN Estimates of Incidence and Mortality Worldwide for 36 Cancers in 185 Countries. Ca Cancer J Clin. 2018;68:394424.

2. Global Cancer Observatory: Cancer Today. Lyon, France: International Agency for Research on Cancer [Internet]. 2020 [cited 2021 Apr 2]. Available from:

https://gco.iarc.fr/today/data/factsheets/populations/910-eastern-africa-fact-sheets.

3. Memirie ST, Habtemariam MK, Asefa M, Deressa BT, Abayneh G, Tsegaye B, Abraha MW, Ababi G, Jemal A, Rebbeck TR, Verguet S. Estimates of Cancer Incidence in Ethiopia in 2015 Using PopulationBased Registry Data. J Glob Oncol. 2018:1-11.

4. Wenzel L, Vergote I, Cella D. Quality of life in patients receiving treatment for gynecologic malignancies: special considerations for patient care. Int J Gynaecol Obstet. 2003 Oct;83 Suppl 1:211-29. doi: 10.1016/s0020-7292(03)90123-8. PMID: 14763177.

5. Numico G, Longo V, Courthod G, Silvestris N. Cancer Survivorship: Long-term Side-effects of Anticancer Treatments of Gastrointestinal Cancer. Curr Opin Oncol. 2015;27:351-7. 
6. Grosek J, Novak J, Kitek K, Bajric A, Majdic A, Kosir JA. Health-related quality of life in Slovenian patients with colorectal cancer: a single tertiary care center study. Radiol Oncol. 2019;53(2):231-7.

7. Arndt V, Merx H, Stegmaier C, Ziegler H, Brenner H. Quality of Life in Patients With Colorectal Cancer 1 Year After Diagnosis Compared With the General Population: A Population-Based Study. J Clin Oncol. 2004;22(23):4829-36.

8. Jansen $L$, Koch L, Brenner $H$, Arndt V. Quality of life among long-term ( $P 5$ years) colorectal cancer survivors - Systematic review. Eur J Cancer [Internet]. 2010;46(16):2879-88. Available from: http://dx.doi.org/10.1016/j.ejca.2010.06.010

9. Blazeby JM, Avery K, Sprangers M, Pikhart H, Fayers P, Donovan J. Health-Related Quality of Life Measurement in Randomized Clinical Trials in Surgical Oncology. J Clin Oncol. 2015;24(19):317884.

10. World Health Organization. Division of Mental Health and Prevention of Substance Abuse. (1997). WHOQOL : measuring quality of life. World Health Organization.

https://apps.who.int/iris/handle/10665/63482

11. Bonnetain F, Borg C, Adams RR, Ajani JA, Benson A, Bleiberg H, et al. How health-related quality of life assessment should be used in advanced colorectal cancer clinical trials. Ann Oncol [Internet]. 2017;28(9):2077-85. Available from: http://dx.doi.org/10.1093/annonc/mdx191

12. Tamburini M. Health-related quality of life measures in cancer. Ann Oncol. 2001;12:8-10.

13. Pallis AG, Mouzas IA. Instruments for quality of life assessment in patients with gastrointestinal cancer. Anticancer Res. 2004 May-Jun;24(3b):2117-21. PMID: 15274411.

14. Luckett T, King MT, Butow PN, Heading G. Choosing between the EORTC QLQ-C30 and FACT-G for measuring health-related quality of life in cancer clinical. Ann Oncol. 2011;22(10):2179-90.

15. Arraras JI, Suárez J, Arias de la Vega F, Vera R, Asín G, Arrazubi V, Rico M, Teijeira L, Azparren J. The EORTC Quality of Life questionnaire for patients with colorectal cancer: EORTC QLQ-CR29 validation study for Spanish patients. Clin TransI Oncol. 2011 Jan;13(1):50-6. doi: 10.1007/s12094-011-0616-y. PMID: 21239355.

16. Shen M, Chen L, Ho T, Shih Y, Huang C, Chie W. Validation of the Taiwan Chinese version of the EORTC QLQ-CR29 to assess quality of life in colorectal cancer patients. BMC Cancer. 2018;1-10.

17. Ihn MH, Lee S, Son IT, Park JT, Oh H, Kim D, et al. Cultural adaptation and validation of the Korean version of the EORTC QLQ-CR29 in patients with colorectal cancer. Support Care Cancer. 2015;

18. Lin J, Zhang L, Wu D, Xi Z, Wang X, Lin Y, et al. Validation of the Chinese version of the EORTC QLQCR29 in patients with colorectal cancer. World J Gastroenterol. 2017;23(10):1891-8.

19. Kifle M, Abdella K, Moge T, Tsegaye T, Moges A. National Cancer Control Plan Of Ethiopia. 2015.

20. Deressa BT, Cihoric N, Tefesse E, Assefa M, Zemenfes D. Multidisciplinary Cancer Management of Colorectal Cancer in Tikur Anbessa Specialized Hospital, Ethiopia. J Glob Oncol. 2019 Oct;5:1-7. doi: 10.1200/JG0.19.00014. PMID: 31589543; PMCID: PMC6825246. 
21. Norman GR, Streiner DL. Biostatistics - The Bare Essentials. 4th ed. Mehta L, McKeon M, editors. People's Medical Publishing House. USA; 2014. p. 937.

22. Fayers PM, Machin D. Quality of Life: Assessment, Analysis and Interpretation. Chichester:John Wiley \& Sons; 2000.

23. Whistance RN, Conroy T, Chie W, Costantini A, Sezer O, Koller M, et al. Clinical and psychometric validation of the EORTC QLQ-CR29 questionnaire module to assess health-related quality of life in patients with colorectal cancer. Eur J Cancer [Internet]. 2009;45(17):3017-26. Available from: http://dx.doi.org/10.1016/j.ejca.2009.08.014

24. Dewolf L, Koller M, Velikova G, Johnson C, Scott N, Bottomley A et al. EORTC Quality of Life Group translation procedure. 3rd ed. Brussels, Belgium: EORTC Quality of Life Group, 2009. 32 p.

25. Koller M, Lorenz W. Quality of life: A deconstruction for clinicians. J R Soc Med. 2002;95(10):481-8.

26. Fayers PM, Aaronson NK, Bjordal K, Groenvold M, Curran D, Bottomley A, on behalf of the EORTC Quality of Life Group. The EORTC QLQ-C30 Scoring Manual. 3rd ed. Brussels, Belgium: EORTC Quality of Life Group, 2001.

27. Stiggelbout AM, Kunneman M, Baas-thijssen MCM, Neijenhuis PA. The EORTC QLQ-CR29 quality of life questionnaire for colorectal cancer: validation of the Dutch version. Qual Life Res. 2016;25:1853-8.

28. Goodwin LD, Leech NL. Understanding correlation: Factors that affect the size of r. J Exp Educ. 2006;74(3):249-66.

29. Tiggemann M, McCourt A. Body appreciation in adult women: Relationships with age and body satisfaction. Body Image [Internet]. 2013;10(4):624-7. Available from:

http://dx.doi.org/10.1016/j.bodyim.2013.07.003 